\title{
PREVENCIÓN, DIAGNÓSTICO Y TRATAMIENTO DE INFECCIONES PEDIÁTRICAS EN DESASTRES NATURALES
}

\author{
Flavia Morán $1, a$, Theresa J. Ochoa1,2,b
}

\begin{abstract}
RESUMEN
El objetivo de esta revisión es brindar pautas sobre el diagnóstico, tratamiento y prevención de las enfermedades infecciosas más frecuentes en niños, en situaciones de desastres naturales, como las inundaciones y huaicos ocurridos en el verano del 2017 en Perú. Está dirigido a los médicos y personal de salud del primer nivel de atención. Se discute el manejo de las enfermedades diarreicas, respiratorias, de piel y ojos, enfermedades asociadas a vectores como el dengue, chikungunya y zika, y zoonosis como la leptospirosis. Se enfatiza en los aspectos básicos de la educación sanitaria a la población, sobre todo en las medidas preventivas como el uso de agua segura, lactancia materna, inmunizaciones, lavado de manos y el control de vectores.
\end{abstract}

Palabras clave: desastres naturales, enfermedades transmisibles, niño (fuente: DeCS BIREME).

\section{PREVENTION, DIAGNOSIS, AND TREATMENT OF PEDIATRIC INFECTIONS DURING NATURAL DISASTERS}

\begin{abstract}
The objective of this review was to provide guidelines regarding the diagnosis, treatment, and prevention of the most common infectious diseases in children during natural disasters, including floods such as those that occurred in the summer of 2017 in Peru. This instrument should be used by physicians and health personnel working in primary health care. The management of diarrheal, respiratory, skin, and eye diseases, vector-transmitted diseases such as dengue, chikungunya, and Zika, and zoonoses such as leptospirosis is discussed. Emphasis is placed on the essential aspects of health education for the population, particularly preventive health, including the use of potable water, breastfeeding, immunization, hand washing, and vector control.
\end{abstract}

Key words: natural disasters, communicable diseases, child (source: MeSH NLM).

\section{INTRODUCCIÓN}

El Perú está situado en el llamado círculo de fuego del Pacífico, motivo por el cual está permanentemente expuesto a eventos naturales que derivan en emergencias y desastres ${ }^{(1)}$. Eventos como lluvias intensas, inundaciones y huaicos han causado, en el verano del 2017, daños severos, principalmente en la costa norte del país, después de casi 20 años del mega Niño de 1997-1998. Un aumento de enfermedades infecciosas se puede evidenciar días, semanas o incluso meses después del inicio de un desastre, principalmente por el desplazamiento poblacional y la exacerbación de factores de riesgo para la transmisión de infecciones ${ }^{(2)}$.

Condiciones de saneamiento deficiente, falta de agua, hacinamiento, mal estado nutricional por falta de alimentos, baja cobertura basal de inmunizaciones y un aumento de las zoonosis ponen en mayor riesgo a la población ${ }^{(2-4)}$. En este contexto, la presente revisión, dirigida a médicos del primer nivel de atención, tiene como objetivo brindar mensajes clave y pautas sobre el diagnóstico, tratamiento y prevención de las infecciones más frecuentes en situaciones de desastre en la población pediátrica, que es considerada una de las más vulnerables.

\section{ENFERMEDADES ASOCIADAS AL AGUA Y ALIMENTOS}

Reportes de El Niño de 1982-1983 en el Perú muestran que las enfermedades diarreicas incrementaron en un $176 \%$ en la población infantil (1). Asimismo, estudios de El Niño de 1997-1998 reportaron un incremento anormal del número de casos de diarrea en niños que no podía

\footnotetext{
Facultad de Medicina Alberto Hurtado, Universidad Peruana Cayetano Heredia, Lima, Perú.

Instituto de Medicina Tropical "Alexander von Humboldt", Universidad Peruana Cayetano Heredia. Lima, Perú.

a Estudiante de Medicina; ${ }^{b}$ médico infectólogo Pediatra

Recibido: 09/04/2017 Aprobado: 20/09/2017 En línea: 27/11/2017
}

Citar como: Morán F, Ochoa TJ. Prevención, diagnóstico y tratamiento de infecciones pediátricas en desastres naturales. Rev Peru Med Exp Salud Publica. 2017;34(4):723-30.doi:10.17843/rpmesp.2017.344.2810 
ser explicado por la variabilidad regular estacional ${ }^{(5,6)}$. La asociación se establece por las temperaturas elevadas que incrementan la sobrevida y persistencia de muchos de los microorganismos causantes de diarrea y el escaso acceso a agua segura en situaciones de desastre ${ }^{(7)}$.

La diarrea, por sus características, puede ser acuosa o disentérica. La primera se caracteriza por deposiciones líquidas o semilíquidas, de gran volumen, acompañados o no de vómitos, fiebre y dolor abdominal. Los patógenos más frecuentes en niños son: virus (norovirus, rotavirus), bacterias (Shigella, Campylobacter, Salmonella, E. coli diarrogénicas, Vibrio, Aeromonas) y parásitos (Giardia, Crysptosporidium, Isospora, Cyclospora, Microsporidium). La diarrea disentérica presenta sangre mezclada con las deposiciones, usualmente semilíquidas o pastosas, no de gran volumen. Pueden estar acompañadas de moco, vómitos, fiebre, dolor abdominal, pujo y tenesmo. Los patógenos más frecuentes en niños son: Shigella, Salmonella, Campylobacter, Yersinia, Clostridium, E. coli productora de shigatoxina o enterohemorrágica (STEC), E. coli enteroinvasiva (EIEC), y los parásitos Entamoeba histolytica y Balantidium coli ${ }^{(8)}$.
El primer paso en el manejo de una diarrea es determinar el estado de deshidratación del niño mediante tres signos clave: sed, sensorio y signo del pliegue (3S), para hidratarlo según el plan A-B-C:

Si el niño bebe normalmente, está alerta, el pliegue cutáneo vuelve a su estado normal rápidamente, los ojos no están hundidos, tiene lágrimas y mucosas orales húmedas, entonces no tiene signos de deshidratación y se puede tratar en el hogar según las cinco reglas del Plan A (Tabla 1). El niño debe recibir mayor cantidad de líquidos para reemplazar las pérdidas (leche materna, agua de cocción de cereales, sopas, agua simple) a libre demanda (media taza después de cada deposición para niños menores de 2 años, y una taza para niños mayores de 2 años). Si el niño tiene alto riesgo de deshidratarse, porque la diarrea es muy intensa (más de tres vómitos en una hora, o más de cuatro deposiciones en 4 horas, o más de diez en 24 h, o son deposiciones de alto volumen) debe recibir sales de hidratación oral (SRO) para reponer adecuadamente la pérdida de líquidos y electrolitos. Esto debe hacerse, idealmente, en el establecimiento de salud.

Tabla 1. Las cinco reglas del Plan A: tratamiento en el hogar* para prevenir la deshidratación y la desnutrición**

\begin{tabular}{|c|c|}
\hline Regla & Descripción \\
\hline $\begin{array}{l}\text { Aumente la ingesta de líquidos apropia- } \\
\text { dos para la edad en mayor cantidad que } \\
\text { lo habitual. }\end{array}$ & $\begin{array}{l}\text { Los mejores líquidos son los preparados caseros en base a cereales cocidos } \\
\text { (arroz, maíz, avena, cebada, quinua), sopas o caldos. } \\
\text { Deben administrarse a libre demanda, pero se recomienda dar como mínimo } 100 \mathrm{~mL} \\
\text { (media taza) a niños menores de } 2 \text { años y } 200 \mathrm{~mL} \text { (una taza) a los niños mayores de } 2 \\
\text { años con cada deposición. } \\
\text { Los líquidos deben darse de manera muy lenta, usando una cucharita o jeringa por vía } \\
\text { oral, para evitar el vómito }\end{array}$ \\
\hline Continuar con la alimentación habitual. & $\begin{array}{l}\text { Los alimentos deben darse con una adecuada frecuencia, cantidad y consistencia } \\
\text { (no dar "dietas"). } \\
\text { Continuar con la lactancia materna. } \\
\text { No se debe diluir los alimentos, se prefieren los sólidos. } \\
\text { Se puede dar menos cantidad de alimento, pero más veces al día para mejorar la } \\
\text { tolerancia. }\end{array}$ \\
\hline $\begin{array}{l}\text { Reconocer signos de deshidratación y } \\
\text { alarma y cuándo regresar de inmediato } \\
\text { al establecimiento. }\end{array}$ & $\begin{array}{l}\text { Niño empeora o no se ve bien. } \\
\text { Letargia, irritación o hiperactividad. } \\
\text { Más de cuatro deposiciones en } 4 \text { h y vómitos a repetición. } \\
\text { Sed intensa, o no come ni bebe normalmente. } \\
\text { Fiebre o sangre en las heces. } \\
\text { Niño no mejora al tercer día. }\end{array}$ \\
\hline $\begin{array}{l}\text { Enseñar a evitar futuros episodios de } \\
\text { diarrea. }\end{array}$ & $\begin{array}{l}\text { Continuar con la lactancia materna. } \\
\text { Adecuada nutrición e inicio de la ablactancia a los } 6 \text { meses. } \\
\text { Lavado de manos. } \\
\text { Uso de agua segura. } \\
\text { Adecuada eliminación de las excretas. } \\
\text { Estar al día en todas las vacunas. }\end{array}$ \\
\hline Administrar suplemento de zinc. & $\begin{array}{l}\text { El zinc disminuye la duración de la diarrea y las recurrencias. } \\
\text { Está recomendada para los niños mayores de } 6 \text { meses. } \\
\text { La tableta debe disolverse en } 5 \mathrm{~mL} \text { de líquido a una dosis de } 20 \mathrm{mg} \text { de zinc/día por } \\
7-10 \text { días. }\end{array}$ \\
\hline
\end{tabular}

*En caso el niño califique como Plan A, pero tenga un alto riesgo de deshidratación (tres vómitos en una hora o más de cuatro deposiciones en $4 \mathrm{~h}$ ), haya estado en Plan B o C, o viva en una zona de difícil acceso, no se le enviará a casa y se aplicará la terapia de rehidratación oral en el centro de salud.

${ }^{* *}$ Adaptado de la Guía Técnica de EDA del MINSA 
Si el niño presenta mucha sed o bebe ávidamente, está irritable o tiene signo del pliegue (pliegue cutáneo desaparece en menos de dos segundos), entonces tiene deshidratación moderada y debe ser atendido en un establecimiento de salud con el Plan B. Se debe administrar SRO a libre demanda, como mínimo 50-100 mL/kg en 3-4 h, por boca muy lentamente o mediante una sonda nasogástrica si el niño presenta muchos vómitos. Debe evaluarse al niño constantemente.

Si el niño ya no es capaz de beber, esta somnoliento, estuporoso o comatoso, o tiene el pliegue cutáneo que desaparece muy lentamente (más de dos segundos), entonces tiene deshidratación grave y debe recibir el Plan $\mathrm{C}$ en el establecimiento de salud. Si el niño tiene shock debe recibir, primero, un bolo de solución salina (cloruro de sodio al 0,9\%) $20 \mathrm{~mL} / \mathrm{kg}$ EV en 10-15 min. La hidratación debe realizarse con solución polielectrolítica o lactato de Ringer, $100 \mathrm{~mL} / \mathrm{kg} \mathrm{EV}$ en $6 \mathrm{~h}$ para niños menores de 12 meses (30 mL/kg en $1 \mathrm{~h}$, seguido de $70 \mathrm{~mL} / \mathrm{kg}$ en $5 \mathrm{~h}$ ) y en $3 \mathrm{~h}$ para niños mayores de 12 meses $(30 \mathrm{~mL} / \mathrm{kg}$ en $30 \mathrm{~min}$ seguido de $70 \mathrm{~mL} / \mathrm{kg}$ en 2,5 h) (para más información ver la Guía Técnica de EDA del Ministerio de Salud).

El tratamiento con antibióticos está reservado para la diarrea disentérica. En menores de 1 año hay mayor probabilidad de infección por Campylobacter, que es cubierto por eritromicina o azitromicina. En niños mayores de 1 año aumenta el riesgo de Shigella, que puede ser tratado con ciprofloxacina para casos graves o con furazolidona o azitromicina para casos leves. En nuestro país no debemos usar trimetropim-sulfametoxazol, también conocido como cotrimoxazol, pues la mayoría de patógenos entéricos son resistentes a este antibiótico ${ }^{(8,9)}$

Un patógeno de importancia es el Vibrio cholerae. La última epidemia de cólera en el Perú fue en el año 1991; actualmente no existen casos de cólera, pero es una enfermedad sujeta a vigilancia epidemiológica. Se debe sospechar en casos de diarrea líquida, profusa, de aparición brusca, con deposiciones de alto flujo como "agua de lavado de arroz", acompañado de vómitos y que lleva rápidamente a la deshidratación. Estos pacientes necesitan una hidratación enérgica endovenosa y con SRO, según las pautas descritas más arriba; sin embargo, pueden requerir cantidades excepcionalmente grandes de SRO con volúmenes promedio de $200-300 \mathrm{~mL} / \mathrm{kg}$ para reponer las pérdidas continuas y abundantes en las heces líquidas. Los pacientes con cólera deben recibir antibióticos para disminuir la duración y severidad de la enfermedad y disminuir la transmisión. Los niños pueden recibir azitromicina, eritromicina, furazolidona o doxiciclina (para más información ver la Guía Técnica de EDA del Ministerio de Salud).

Otro patógeno a tomar en cuenta es el virus de la hepatitis A, por su mecanismo de transmisión fecal-oral, y a través de agua y alimentos. Este virus es muy resistente al calor por lo que puede sobrevivir semanas en el agua, alimentos y el suelo. En el Perú, la hepatitis A tiene un patrón de endemicidad intermedia en niños y adolescentes ${ }^{(10)}$. El cuadro clínico se presenta con un periodo prodrómico de aproximadamente 7 días, caracterizado por síntomas inespecíficos como fiebre, astenia, vómitos, náuseas, dolor abdominal y diarrea. La ictericia se presenta en menos del $10 \%$ de los niños menores de 6 años y suele durar un par de semanas, mientras que en mayores de 14 años se presenta en un $70-80 \%$ y suele durar varias semanas. La mayoría de casos en niños tiene una evolución favorable en base a un manejo ambulatorio con reposo, líquidos y alimentación fraccionada ${ }^{(11)}$.

La fiebre tifoidea, causada por diferentes especies de Salmonella, es también una enfermedad producida por contaminación fecal-oral y por comer alimentos contaminados. Se caracteriza por una infección sistémica, con fiebre elevada y persistente por más de 5 días, malestar general, náuseas, dolor abdominal, cefalea y, en algunos casos, diarrea o estreñimiento. Los niños pueden tener hepatoesplenomegalia y un rash transitorio. Pruebas serológicas (aglutinaciones) apoyan el diagnóstico, sin embargo, estas tienen baja sensibilidad y especificidad, por lo que se realiza la confirmación mediante hemocultivo. El tratamiento es con cloranfenicol, criprofloxacina, azitromicina o ceftriaxona ${ }^{(12)}$.

La medida preventiva más importante para las infecciones asociadas al agua es el uso de agua segura para beber y lavar los alimentos (frutas y verduras). La recomendación en orden de prioridad es usar agua embotellada; en segundo lugar, agua hervida y, en caso el agua sea turbia, se puede filtrar a través de un paño o dejar que se asiente y sacar el agua clara; en tercer lugar, se puede usar agua clorada. Los desinfectantes como el cloro/lejía pueden matar a la mayoría de los virus y bacterias que causan enfermedades, pero no son tan efectivos en el control de organismos más resistentes, como los parásitos Cryptosporidium y Giardia. La cantidad dependerá del porcentaje de hipoclorito de sodio que figure en la etiqueta (Tabla 2). Se debe mezclar, esperar 30 min y almacenar el agua en recipientes limpios con tapa ${ }^{(13)}$.

Otras medidas preventivas son el lavado de manos, sobre todo en tres momentos clave: después de ir baño o cambiar los pañales al bebé; antes de preparar los alimentos y antes de comer; la adecuada eliminación de excretas y de residuos sólidos; y estar al día con todas las vacunas pediátricas básicas (incluyendo rotavirus). La lactancia materna es la intervención más costo-efectiva para disminuir los casos y las muertes asociadas a diarrea. La leche materna no solo es una fuente de alimento no contaminado, sino también es una fuente de factores protectores contra las infecciones, como las inmunoglobulinas, oligosacáridos y glicoproteínas como la lactoferrina. Los niños menores de 6 meses deben recibir lactancia materna exclusiva, sin otras leches $u$ otros líquidos. Se debe continuar la lactancia hasta los 2 
Tabla 2. Pautas para preparar agua clorada* en base a hipoclorito de sodio (cloro o lejía)**

\begin{tabular}{lccc}
\hline & \multicolumn{3}{c}{ Concentración de hipoclorito de sodio } \\
\hline & $1 \%$ & $\begin{array}{c}4-6 \%, 8,25 \% \\
(\text { los más comunes) }\end{array}$ & Porcentaje no conocido \\
Número de gotas por litro & 10 gotas/L & 2 gotas/L & 10 gotas/L \\
\hline
\end{tabular}

*Si el agua está turbia, coloreada o muy fría, previamente filtrar a través de un paño o tela o dejar que se asiente y sacar el agua clara. Añadir el doble de la cantidad de cloro que se indica.

${ }^{* *}$ Adaptado del CDC. Making Water Safe in an Emergency ${ }^{(12)}$

años de edad. La leche materna es un alimento seguro y accesible en un contexto de desastres naturales. Se debe evitar el uso de biberones y fórmulas infantiles que pueden involucrar poca higiene y uso de agua contaminada.

\section{ENFERMEDADES RESPIRATORIAS}

Los refugios no planificados y campamentos temporales que se establecen durante los desastres naturales condicionan ambientes hacinados, con mala ventilación, que incrementan, principalmente, las infecciones agudas respiratorias ${ }^{(2,4)}$. Adicionalmente, la falta de agua para el lavado de manos, aumenta la posibilidad de transmitir los microorganismos que se encuentran en las manos por la contaminación al toser, estornudar o tocar la nariz con secreciones.

Las infecciones respiratorias altas son las más frecuentes, incluyendo el resfrío común, faringitis y otitis. En niños pequeños (menores de 4 años), la mayoría de las faringitis o rinofaringitis o faringoamigdalitis son de origen viral (9095\%). El cuadro clínico se caracteriza por la presencia de rinorrea, tos y fiebre. Al examen, la orofaringe esta congestionada y las amígdalas pueden tener o no exudados blanquecinos. Estas infecciones no requieren antibióticos, solo antipiréticos o antiinflamatorios (paracetamol o ibuprofeno). Por lo general, la fiebre dura entre 5-7 días. $\mathrm{Si}$ luego de este período la fiebre o la tos persisten o empeoran, el niño debe ser reevaluado, para descartar una sobreinfección bacteriana ${ }^{(12)}$.

Una entidad importante es la neumonía adquirida en la comunidad, pues causa el $15 \%$ de las muertes en niños menores de 5 años en países en vías de desarrollo ${ }^{(14)}$. Los niños pueden presentar tos, fiebre, dificultad para respirar y respiración rápida o taquipnea. La taquipnea se establece según la edad: para lactantes entre 2 y 12 meses es $>50$ respiraciones por minuto (rpm); para niños entre 1 y 5 años $>40 \mathrm{rpm}$, y para niños $\geq 5$ años $>28 \mathrm{rpm}{ }^{(15)}$.

Es importante poder diferenciar una neumonía viral de una bacteriana para determinar el tratamiento; sin embargo, esto no es fácil la mayoría de las veces. Ambas pueden ser precedidas de síntomas respiratorios altos; las bacterianas suelen tener fiebre más alta, crépitos, matidez a la percusión y estertores; la neumonía viral suele tener sibilancias, roncus, estertores y subcrépitos. La amoxicilina oral es el antibiótico de elección para la neumonía bacteriana a una dosis de 90 $\mathrm{mg} / \mathrm{kg} / \mathrm{día}$ en dos dosis durante 7 días ${ }^{(16)}$. En nuestro país no debemos usar trimetoprim-sulfametoxazol, pues la mayoría de patógenos respiratorios, sobre todo el neumococo, son resistentes a este antibiótico ${ }^{(17)}$. Idealmente, en todo niño con neumonía se debe determinar la saturación de oxígeno y administrarlo si hay hipoxemia. Los signos de severidad son las retracciones de la pared torácica inferior, aleteo nasal y quejido, en niños pequeños ${ }^{(18)}$. Los signos de peligro en un niño con neumonía grave son la cianosis central, la inhabilidad de beber o lactar, vómitos persistentes, convulsiones, letargia o estar inconsciente, y estridor en un niño calmado o con desnutrición severa. Estos pacientes deber recibir ampicilina (o penicilina) más gentamicina, y deben referirlo a un centro de mayor capacidad resolutiva ${ }^{(19)}$.

Las medidas preventivas para las infecciones respiratorias agudas son la adecuada ventilación, el lavado de manos, la lactancia materna y estar al día con todas las vacunas pediátricas básicas (incluyendo la vacuna contra el virus de la influenza, neumococo, Haemophilus influenzae tipo b [Hib] y pertussis; estas dos últimas son parte de la vacuna pentavalente).

\section{ENFERMEDADES DE LA PIEL Y OJOS}

Los traumatismos causados por golpes o aplastamiento son frecuentes en los desastres naturales ${ }^{(3)}$. En general, las heridas tienen un alto riesgo de contaminación con bacterias Gram positivas, como el estafilococo y el estreptococo, por la exposición a tierra y barro. En la población infantil el impétigo, causado principalmente por el Streptococcus pyogenes del grupo A (GAS) y por Staphylococcus aureus, es la infección bacteriana cutánea más frecuente ${ }^{(8)}$; esta predominó en las zonas de desastre durante el periodo de El Niño de 1997-1998 ${ }^{(20)}$. El impétigo se presenta como vesículas pustulosas superficiales y costras amarillentas (mielicéricas). La erisipela es otro tipo de infección que afecta la dermis y el sistema linfático y se presenta como una lesión eritematosa, de bordes elevados y bien delimitados que suele localizarse en la cara en infantes; su principal agente causal también es el GAS. La celulitis es una infección de las dermis superficial 
y profunda, y se presenta como una mácula eritematosa, caliente, dolorosa y con bordes difusos a diferencia de la erisipela; el principal agente causal es el Staphylococcus aureus ${ }^{(8)}$. Otro patógeno a tener en cuenta en la infección de heridas es el Clostridium tetani, que se contagia a través de tierra contaminada con sus esporas ${ }^{(21)}$. Un factor de riesgo adicional a las heridas causadas por trauma son las miliarias (dermatitis vesiculosas o pustulosas) que se presentan en temperaturas altas y sudoración profusa. La miliaria puede sobre infectarse por el hacinamiento y las escasas condiciones sanitarias y derivar en una de las infecciones bacterianas presentadas anteriormente ${ }^{(20)}$.

La mayoría de infecciones de la piel y los tejidos blandos pueden ser tratados de forma ambulatoria, con una adecuada higiene, antibióticos tópicos (ejem. mupirocina) $\mathrm{y}$, en algunos casos, antibióticos orales sistémicos. El tratamiento de elección para las infecciones de piel en general es la dicloxacilina oral $(15-25 \mathrm{mg} / \mathrm{kg} / \mathrm{día}$ dividido cada $6 \mathrm{~h}$ ), dado que no es fácil diferenciar clínicamente las infecciones por estreptococos y estafilococos, y este antibiótico cubre ambos ${ }^{(8)}$. Otras opciones orales son las cefalosporinas de primera generación (ejem. cefalexina), clindamicina o el trimetoprim-sulfametoxazol. Tanto la clindamicina como el cotrimoxazol son útiles, sobre todo si se sospecha Staphylococcus aureus meticilino resistente o MRSA.

El Niño de 1997-1998, con sus altas temperaturas y condiciones húmedas, también evidenció un aumento de la incidencia de tiñas y dermatitis por el insecto Paederus irritans. Las lluvias posteriores destruyeron el hábitat del insecto lo cual lo desplazó a zonas más urbanas de Piura, Tumbes y Lambayeque en donde se presentaron plagas ocasionando brotes de una dermatitis de contacto dolorosa a la que la población llamó "latigazo" porque las lesiones que produce el insecto son lineales y eritematosas ${ }^{(20,22)}$.

Por otro lado, el exceso de polvo y el lavado con agua contaminada también aumentan el riesgo de conjuntivitis, como ocurrió en Ica en El Niño de 1997-1998. Los principales síntomas son la picazón, ardor, el lagrimeo constante, dolor y enrojecimiento de los ojos. Los principales agentes causales son los virus y, en menor medida, las bacterias. La infección bacteriana suele tener una secreción purulenta, gruesa, amarilla, blanca o verde, mientras que la viral o alérgica tienen una descarga más acuosa con un componente escaso que es más un moco que pus. No hay un tratamiento específico para la conjuntivitis viral. Para la bacteriana puede usarse soluciones oftálmicas con eritromicina, polimixina/bacitracina, ciprofloxacina, gentamicina o tobramicina. En niños pequeños se prefiere el ungüento a las gotas $(1,25 \mathrm{~cm} 4$ veces al día durante 5 a 7 días) ${ }^{(23)}$.

Las medidas preventivas incluyen una buena higiene, uso de botas para protección y estar al día con todas las vacunas pediátricas básicas (incluyendo la vacuna contra el tétano, DPT). Para la miliaria, el baño repetido de los niños pequeños durante la horas de mayor calor y una adecuada ventilación ${ }^{(20)}$. Sin embargo, son medidas que se ven limitadas por el abastecimiento de agua segura y los refugios disponibles.

\section{ENFERMEDADES ASOCIADAS A VECTORES}

Los desastres naturales incrementan los factores de riesgo para enfermedades preexistentes de alto nivel endémico. En el Perú, el mosquito Aedes aegypti transmiten el dengue, chikungunya, zika, y fiebre amarilla urbana según la región. Actualmente, los vectores de la fiebre amarilla selvática son Haemagogus sp. y Sabethes sp. Mientras que las inundaciones iniciales pueden eliminar la proliferación de mosquitos existente, agua estancada causada por fuertes lluvias, o el desborde de ríos, puede crear nuevos sitios de cría. Las elevadas temperaturas disminuyen el periodo de incubación del mosquito ${ }^{24)}$; los contenedores artificiales para acumular agua por la interrupción de su suministro propician el crecimiento de las larvas ${ }^{(4)}$.

Estas enfermedades virales se caracterizan por cuadros febriles con rash, cefalea, dolor muscular y articular, y malestar general. Las diferencias clínicas entre el dengue, chikungunya y zika se resumen en la Tabla 3. En general, en el zika predomina el rash y la conjuntivitis, mientras que en el chikungunya la artralgia y el rash.

El cuadro clínico característico del dengue es fiebre de menos de 7 días, cefalea intensa, dolor retroocular, mialgias (rompe huesos), artralgias, rash o exantema leve, náuseas y vómitos. El $80 \%$ de casos son leves, sin embargo, entre el cuarto y séptimo día, al bajar la fiebre, un pequeño grupo puede presentar signos de alarma (Tabla 4) y volverse un cuadro grave. En la población pediátrica, los niños menores de 2 años requieren un especial cuidado con observación permanente entre 24 y 48 h; se requiere hospitalizarlos.

Tabla 3. Comparación de las características clínicas del zika, dengue y chikungunya*

\begin{tabular}{lccc}
\hline Características & Zika & Dengue & Chikungunya \\
\hline Fiebre & ++ & +++ & +++ \\
Rash & +++ & + & ++ \\
Conjuntivitis & +++ & - & - \\
Artralgia & ++ & + & +++ \\
Mialgia & + & ++ & + \\
Cefalea & + & ++ & ++ \\
Hemorragia & - & ++ & - \\
Shock & - & + & - \\
\hline
\end{tabular}

*Adaptado del CDC. Zika virus - What clinicians need to know? ${ }^{(28)}$ 
Tabla 4. Signos de alarma del dengue*

\begin{tabular}{l}
\hline Dolor abdominal intenso y continuo \\
Dolor torácico o disnea \\
Vómitos persistentes \\
Sangrado de mucosas (gingivorragia, epistaxis, metrorragia, \\
e hipermenorrea) \\
Disminución del volumen urinario \\
Somnolencia o irrritabilidad \\
Hepatomegalia >2 cm \\
Hipotermia \\
Derrame seroso al examen clínico o por imágenes: ascitis, \\
derrame pleural o derrame pericárdico \\
Laboratorio: aumento del hematocrito junto con una caída \\
rápida del recuento de plaquetas
\end{tabular}

*Adaptado del MINSA. Lineamientos para el manejo del dengue en zonas de desastres Perú $2017^{(24)}$

De la misma manera, los niños mayores deben quedar en observación si presentan signos de alarma o si se evalúa que por circunstancias sociales tales como vivir lejos del centro de salud, se dificulte su retorno. En el caso de un brote, se debe hacer pruebas diagnósticas en la población pediátrica si son menores de 2 años y/o si tienen signos de alarma. Se pueden usar pruebas rápidas de dengue si están disponibles en el establecimiento de salud o tomar una muestra de sangre y enviarla a los laboratorios de salud pública del país y el INS para que sea procesada. El tratamiento es sintomático, con paracetamol para el dolor y la fiebre. Se recomienda evitar el uso de AINES y tener cuidado con la sobrehidratación en los niños (para más información ver los Lineamientos para el manejo del dengue en zonas de desastres Perú 2017) (25).

La temperatura y humedad también pueden alterar la longevidad y tasas de ovogénesis del mosquito Anopheles sp., transmisor de la malaria y acortar el periodo de maduración del Plasmodium sp., agente causal de la malaria. Tras El Niño de 1997-1998 se observó una extensión de las áreas afectadas por $P$. falciparum ${ }^{(24)}$ que causa la mayoría de casos severos y cuyas manifestaciones en niños se presentan en la Tabla 5. Dentro de la población infantil, los niños pequeños (6-36 meses) son un grupo de alto riesgo para desarrollar enfermedad grave ${ }^{(26)}$.

Las medidas de prevención para enfermedades transmitidas por mosquitos, y que deben ser promovidas mediante actividades extramurales de los centros de salud, son: el uso de repelente, el uso de polos de manga larga y pantalón, y el uso de mosquiteros. En el caso del Aedes aegypti también se debe educar sobre almacenamiento de agua: lavar, escobillar y tapar bien los recipientes, eliminar los objetos en desuso que acumulan agua como llantas y botellas, reemplazar el agua de los floreros por arena húmeda y colocar larvicidas. Adicionalmente, existen intervenciones de control como la fumigación de los hogares ${ }^{(4)}$.
Tabla 5. Manifestaciones severas de malaria por Plasmodium falciparum en niños*

\begin{tabular}{lc}
\hline Características clínicas & Frecuencia \\
\hline Alteración de la conciencia & +++ \\
Distress respiratorio (respiración acidótica) & +++ \\
Convulsiones múltiples & +++ \\
Postración & +++ \\
Shock & + \\
Edema pulmonar (por imágenes) & + - $^{* *}$ \\
Sangrado anormal & $+/_{-}^{* *}$ \\
Ictericia & + \\
\hline
\end{tabular}

${ }^{*}$ Adaptado de WHO. Severe Malaria ${ }^{(25)}$

${ }^{* *}$ Infrecuente

\section{OTRAS ZOONOSIS}

En condiciones de desastre hay destrucción de madrigueras de roedores, con la consecuente muerte o desplazamiento de estos en busca de refugios. Además, existe una mayor exposición a ellos ya que las personas pueden vivir en carpas o en la intemperie. La leptospirosis es una enfermedad que se transmite por el contacto de la piel dañada o de las membranas mucosas con orina de roedores, agua, lodo contaminado o tejido de animales infectados y raramente por el consumo de alimentos contaminados ${ }^{(2)}$.

El diagnóstico de leptospirosis es difícil debido a que sus síntomas se asemejan a los de otras enfermedades como dengue y fiebre tifoidea ${ }^{(27)}$. Además, presenta un amplio espectro clínico que va desde una enfermedad muy leve de síntomas inespecíficos a una enfermedad grave con falla multiorgánica (síndrome de Weil). Un caso probable se define como el paciente con fiebre menor o igual a 7 días, con cefalea, mialgias, artralgias, que puede o no estar acompañada de inyección conjuntival y/o ictericia o evidencia de sangrado o anuria/oliguria y/o proteinuria, que refiera exposición durante las últimas 4 semanas a fuentes de agua, letrinas o contacto con animales enfermos o roedores. Se debería adicionar tratamiento de leptospirosis a pacientes que eran considerados casos probables de dengue y que resultan con pruebas diagnósticas negativas o que presentan síntomas de deterioro como falla hepática, renal o pulmonar. El tratamiento para leptospirosis leve estable en niños hasta $40 \mathrm{~kg}$ es amoxicilina $40 \mathrm{mg} / \mathrm{kg} /$ día dividido en tres dosis (oral) por 7 días. Para los casos moderados a severos se puede usar penicilina, ampicilina o ceftriaxona ${ }^{(26)}$.

Las medidas preventivas son evitar bañarse en aguas estancadas (riachuelos, pozas, charcos), proteger los alimentos del contacto con roedores y otros animales, utilizar calzado de protección y colocar la basura en bolsas cerradas ${ }^{(28)}$. 


\section{CONCLUSIÓN}

Ante eventos naturales como inundaciones, lluvias intensas y huaicos es importante fortalecer los centros de atención primaria para mantener una vigilancia activa, diagnosticar y tratar oportunamente las infecciones, y así disminuir la morbimortalidad en la población pediátrica. Si bien las infecciones en niños son muy diversas, consideramos que las enfermedades asociadas al agua y alimentos (diarrea, disentería, hepatitis A, y fiebre tifoidea), enfermedades respiratorias (faringitis y neumonía), enfermedades asociadas a la piel y ojos (impétigo, celulitis, conjuntivitis), enfermedades asociadas a vectores (dengue, chikungunya y zika) y otras zoonosis (lesptospirosis), son las más importantes en el contexto actual. Se deben promover actividades intra y extramurales para educar a la población en medidas preventivas, como el uso de agua segura, continuidad de la lactancia materna, coberturas altas de inmunizaciones, adecuada ventilación y lavado de manos, uso de calzado protector y control de mosquitos y vectores. Un resumen de las enfermedades infecciosas y medidas de prevención se presentan en la Tabla 6.

Fuente de financiamiento: autofinanciado

Conflictos de interés: los autores declaran no tener conflictos de interés.

Contribuciones de los autores: FM y TJO han participado en la concepción del artículo, su redacción, la revisión crítica y aprobación de la versión final.

Tabla 6. Resumen de enfermedades infecciosas y medidas de prevención

\begin{tabular}{|c|c|c|}
\hline $\begin{array}{l}\text { Tipo de } \\
\text { enfermedades }\end{array}$ & Enfermedades & Prevención \\
\hline $\begin{array}{l}\text { Enfermedades } \\
\text { asociadas } \\
\text { al agua y } \\
\text { alimentos }\end{array}$ & $\begin{array}{l}\text { Diarrea acuosa } \\
\text { Diarrea disentérica } \\
\text { Cólera } \\
\text { Hepatitis A } \\
\text { Fiebre tifoidea }\end{array}$ & $\begin{array}{l}\text { - Uso de agua segura para beber y lavar frutas y verduras. } \\
\text { - Lavado de manos. } \\
\text { - Adecuada eliminación de excretas y de residuos sólidos. } \\
\text { - Estar al día con todas las vacunas pediátricas básicas (incluyendo rotavirus). } \\
\text { - Lacta materna y evitar el uso de biberones y fórmulas infantiles. }\end{array}$ \\
\hline $\begin{array}{l}\text { Enfermedades } \\
\text { respiratorias }\end{array}$ & $\begin{array}{l}\text { Resfrío común } \\
\text { Faringitis } \\
\text { Otitis } \\
\text { Neumonía }\end{array}$ & $\begin{array}{l}\text { - Adecuada ventilación. } \\
\text { - Lavado de manos. } \\
\text { - Lactancia materna. } \\
\text { - Estar al día con todas las vacunas pediátricas básicas (incluyendo la vacuna } \\
\text { contra el virus de la influenza, neumococo, Haemophilus influenzae tipo b } \\
\text { [Hib] y pertussis). }\end{array}$ \\
\hline $\begin{array}{l}\text { Enfermedades } \\
\text { de la piel y } \\
\text { ojos }\end{array}$ & $\begin{array}{l}\text { Impétigo, erisipela, celulitis } \\
\text { Infección por Clostridium tetani } \\
\text { Tiñas } \\
\text { Dermatitis por Paederus irritans } \\
\text { Conjuntivitis }\end{array}$ & $\begin{array}{l}\text { - Buena higiene } \\
\text { - Uso de botas o calzado de protección } \\
\text { - Estar al día con todas las vacunas pediátricas básicas } \\
\text { (incluyendo la vacuna contra el tétano, DPT) } \\
\text { - Baño repetido de los niños pequeños durante las horas de mayor calor y } \\
\text { adecuada ventilación. }\end{array}$ \\
\hline $\begin{array}{l}\text { Enfermedades } \\
\text { asociadas a } \\
\text { vectores }\end{array}$ & $\begin{array}{l}\text { Dengue } \\
\text { Chikungunya } \\
\text { Zika } \\
\text { Malaria }\end{array}$ & $\begin{array}{l}\text { - Uso de repelente y uso de polos de manga larga y pantalón. } \\
\text { - Adecuado almacenamiento de agua (lavar, escobillar y tapar bien los } \\
\text { recipientes, eliminar los objetos en desuso que acumulan agua). } \\
\text { - Colocar larvicidas. } \\
\text { - Usar mosquiteros. }\end{array}$ \\
\hline Otras zoonosis & Leptospirosis & $\begin{array}{l}\text { - Evitar bañarse en aguas estancadas (riachuelos, pozas, charcos). } \\
\text { - Uso de botas o calzado de protección. } \\
\text { - Proteger los alimentos del contacto con roedores y otros animales. } \\
\text { - Colocar la basura en bolsas cerradas. }\end{array}$ \\
\hline
\end{tabular}

\section{REFERENCIAS BIBLIOGRÁFICAS}

1. Ministerio de Salud. Oficina General de Defensa Nacional. Plan sectorial de prevención y atención de emergencias y desastres del sector salud [Internet]. 2004 [citado 3 de abril de 2017]. Disponible en: http://www.minsa.gob.pe/ogdn/cd1/ $\mathrm{pdf} / \mathrm{nls}$ _04/plansectorialsalud.pdf
2. Kouadio IK, Aljunid S, Kamigaki T, Hammad K, Oshitani H. Infectious diseases following natural disasters: prevention and control measures. Expert Rev Anti Infect Ther. [Internet] 2012 [citado 3 abril del 2017] 10(1):95-104.
3. Ahern M, Kovats RS, Wilkinson P, Few R, Matthies F. Global health impacts of floods: epidemiologic evidence. Epidemiol Rev. [Internet] 2005 [citado 3 abril de 2017] 27:36-46. Disponible en: https://academic.oup.com/epirev/articlelookup/doi/10.1093/epirev/mxi004 
4. Watson JT, Gayer M, Connolly MA. Epidemics after Natural Disasters. Emerg Infect Dis. [Internet] 2007 [citado 3 abril de 2017] 13(1):1-5.

5. Checkley W, Epstein LD, Gilman RH, Figueroa D, Cama RI, PatzJA, et al. Effects of EI Niño and ambient temperature on hospital admissions for diarrhoeal diseases in Peruvian children. The Lancet. [Internet] 2000 [citado 3 abril de 2017] 355(9202):442-50.

6. Salazar-Lindo E, Pinell-Salles P, Maruy A, Chea-Woo E. El Niño and diarrhoea and dehydration in Lima, Peru. The Lancet. [Internet] 1997 [citado 3 abril de 2017] 350(9091):1597-8.

7. Ramos W, Miranda J, Valdez W, SotoCabezas M, Martínez C, Tovar JC, et al. Influencia de los fenómenos el Niño y la Niña sobre los episodios de enfermedad diarreica aguda atendidos en establecimientos de salud de la Red Nacional de Epidemiología, década 20002009. Revista Peruana de Epidemiología. [Internet].2012 [citado2 de abrilde2017]. Disponible en: http://www.redalyc.org/ articulo.oa?id=203124341003

8. Maguiña, C. Uso racional de antibióticos. tercera edición. Lima Perú; 2016.

9. Lluque A, Mosquito S, Gomes C, Riveros M, Durand D, Tilley DH, et al. Virulence factors and mechanisms of antimicrobial resistance in Shigella strains from periurban areas of Lima (Peru). Int J Med Microbiol IJMM. [Internet] 2015 [citado 2 de abril de 2017] 305(4-5):480-90.

10. Hernández R, Chaparro E, Díaz C, Carbajal M, Cieza É, Cerpa R. Frecuencia de hepatitis A en niños y adolescentes de cinco ciudades del Perú. Rev Peru Med Exp Salud Pública. [Internet] 2015 [citado 2 de abril de 2017] 32(3):499-503.

11. MinisteriodeSalud.RD410-2012-INSNDG. Guía de Práctica Clínica de Hepatitis Viral Aguda A [Internet]. 2011 [citado 3 de abril de 2017]. Disponible en: http:// www.insn.gob.pe/transparencia/sites/ default/files/RD\%20410-2012.pdf

12. Cherry J, Demmler-Harrison G, Kaplan S, Steinbach W, Hotez P. Feigin and Cherry's Textbook of Pediatric Infectious Diseases. 7 ed. 2013.

13. CDC. Making Water Safe in an Emergency. Water, Sanitation, \& Hygienerelated Emergencies \& and Outbreaks [Internet]. [citado 3 de abril de 2017].
Disponible en: https://www.cdc.gov/ healthywater/emergency/drinking/ making-water-safe.html

14. OMS | Neumonía [Internet]. WHO. [citado 3 de abril de 2017]. Disponible en: http://www.who.int/mediacentre/ factsheets/fs331/es/

15. WHO. The Management of acute respiratory infections in children: practical guidelines for outpatient care [Internet]. 1995 [citado 3 de abril de 2017]. Disponible en: http://apps.who.int/iris/bitstream/10665/41803/1/9241544775_ eng.pdf

16. OPS, Sociedad Peruana de Enfermedades Infecciosas y Tropicales. Guía de práctica clínica: Neumonía adquirida en la comunidad en Niños [Internet]. 2009 [citado 3 de abril de 2017] Disponible en: http://www.speit.org/archivos/Guia nino.pdf

17. Torres N, Velásquez R, Mercado $\mathrm{EH}$, Egoavil M, Horna G, Mejía L, et al. Antibiotic resistance of streptococcus pneumoniae among healthy nasopharyngeal carriers in seven regions of Peru. Rev Peru Med Exp Salud Pública. [Internet] 2013 [citado 3 de abril de 2017] 30(4):575-82.

18. Principi N, Esposito S. Management of severe community-acquired pneumonia of children in developing and developed countries. Thorax. [Internet] 2011 [citado 3 de abril de 2017] 66(9):815-22. Disponible en: http://thorax.bmj.com/ content/66/9/815.long

19. WHO. Revised WHO classification and treatment of childhood pneumonia at health facilities: evidence summaries [Internet]. 2014 [citado 3 de abril de 2017] Disponible en: http://apps.who.int/iris/bitstr eam/10665/137319/1/9789241507813 eng.pdf

20. Bravo W, Bravo F. El efecto del Fenómeno El niño en las enfermedades dermatológicas. Folia Dermatológica Peruana [Internet] 2001 [citado 3 de abril de 2017] 12(3). Disponible en: http://sisbib.unmsm.edu.pe/bvrevistas/folia/Vol12_N3/ trab_origII_2.htm

21. Tempark T, Lueangarun $S$, Chatproedprai S, Wananukul S. Flood-related skin diseases: a literature review. Int J Dermatol. [Internet] 2013 [citado 3 de abril de 2017] 52(10):1168-76.

22. Suarez-Ognio L, Estela-Ayamamani D, Cáceres-Mejía B, Gambirazio-Carbajal
C, Cabrera R. Impacto del fenómeno «El Niño» de 1997-1998 en la salud de la población peruana, riesgo potencial para el 2015. Rev Peru Med Exp Salud Publica. [Internet] 2015 [citado 3 de abril de 2017] 32(2):403-4.

23. Jacobs D, Trobe J, Libmann H. Conjunctivitis [Internet]. Walthman (MA): UpToDate [Internet] 2016 [citado 3 de abril de 2017]. Disponible en: https://www. uptodate.com/contents/conjunctivitis?source $=$ search_result\&search.

24. Huarcaya Castilla E, Rossi Leyva F, Llanos-Cuentas A. Influencia de factores climáticos sobre las enfermedades infecciosas. Rev Medica Hered. [Internet] 2004 [citado 3 de abril de 2017] 15(4):218-24.

25. Ministerio de Salud. RM 210-2017/ MINSA. Lineamientos para el manejo del dengue en zonas de desastres Perú 2017 [Internet]. [citado 5 de abril de 2017]. Disponible en: ftp://ftp2.minsa.gob.pe/ normaslegales/2017/RM_210-2017. PDF

26. WHO. Severe Malaria. Trop Med Int Health. [Internet] 2014 [citado 5 de abril de 2017] 19:7-131. Disponible en: http:// onlinelibrary.wiley.com/doi/10.1111/ tmi.12313_2/epdf

27. Alderman K, Turner LR, Tong S. Floods and human health: a systematic review. Environ Int. [Internet] 2012 [citado 5 de abril de 2017] 47:37-47. Disponible en: https://www.ncbi.nlm.nih.gov/pubmed/22750033

28. Ministerio de Salud NTS 049-MINSA/ DGSP. Norma Técnica de Salud para la Atención Integral de la Persona Afectada con Leptospirosis [Internet]. [citado 5 de abril de 2017]. Disponible en: ftp:// ftp2.minsa.gob.pe/normaslegales/2006/ RM675-2006.pdf

Correspondencia: Theresa J. Ochoa

Dirección: Universidad Peruana Cayetano Heredia. Av. Honorio Delgado 430. San Martín de Porres, Lima 31, Perú. Teléfono: 51-1-319-0000 Anexo: 2715

Correo electrónico: Theresa.Ochoa@upch.pe 